\title{
Ensino do ItAalano Com TeCnOlogias: UM Relato de Experiência sobre a Construção Colaborativa da Motivação
}

\author{
Jadirlete Lopes CabraL *
}

RESUMO: O presente artigo está vinculado ao projeto de pesquisa individual Ensino do italiano em AVA: abordagens, métodos e técnicas, o qual, por sua vez, faz parte do grupo de pesquisa Ensino e Aprendizagem de Línguas Estrangeiras com Novas Tecnologias, certificado pelo CNPq desde 2013. Trata-se de um relato de experiências a partir de inquietações suscitadas pela persistência de um modelo tradicional ainda em vigor no âmbito do Instituto de Letras da UFBA e da forte resistência, por parte dos alunos, a um modelo pautado numa aprendizagem autônoma e colaborativa. Minhas observações estão fundamentadas pela pesquisa-ação, uma vez que foram seguidas as etapas de planejamento, ação, observação e reflexão, aplicados com o intuito de promover mudanças no paradigma de ensino presencial tradicional, visando à inserção das novas tecnologias na prática docente rumo à construção de uma aprendizagem crítica, reflexiva e colaborativa. Fundamentaremos nossas reflexões nos trabalhos de Paulo Freire acerca da pedagogia da autonomia (1996), em Lins e Souza quanto ao letramento digital aplicado às tecnologias educacionais (2016), e em Tripp (2005), quanto às características e funções de uma pesquisa-ação. Os resultados preliminares apontam para um fazer pedagógico com novas tecnologias rumo à construção da aprendizagem autônoma.

PALAVRAS-CHAVE: Ensino de LE; TICs; Língua Italiana; Colaboração; Autonomia da aprendizagem.

ABSTRACT: This article is linked to the individual research project Teaching Italian in AVA: approaches, methods and techniques, which, in turn, is part of the research group Teaching and Learning of Foreign Languages with New Technologies, certified by $\mathrm{CNPq}$ since 2013 .This is an account of experiences based on the concerns raised by the persistence of a traditional model still in force within the UFBA Institute

\footnotetext{
* Universidade Federal da Bahia, Salvador (Brasil) - jadecabral2017@gmail.com DOI: http://dx.doi.org/10.11606/issn.2238-8281.v0i36p37-46
} 
of Letters and the strong resistance on the part of the students to a model based on autonomous and collaborative learning . Our observations are based on action research, since the stages of planning, action, observation and reflection were followed, with the aim of promoting changes in the paradigm of traditional classroom teaching, aiming at the insertion of new technologies in teaching practice towards critical learning, reflective and collaborative learning. We will base our reflections on Paulo Freire's work on the pedagogy of autonomy (1996), in Lins e Souza regarding digital literacy applied to educational technologies (2016), and in Tripp (2005). characteristics and functions of an action research. The preliminary results point to a pedagogical approach with new technologies towards the construction of autonomous learning.

KEYWORDS: Teaching of foreign Languages; Teaching with New Technologies; Italian Language; Collaboration; Autonomous learning .

ABSTRACT: IL presente articolo è collegato al progetto di ricerca individuale Insegnamento dell'italiano in AVA: approcci, metodi e tecniche, il quale, a sua volta, fa parte del gruppo di ricerca, Insegnamento e Apprendimento delle Lingue Straniere con Nuove Tecnologie, certificato dal CNPq sin dal 2013. Si tratta di un resoconto di esperienze originate dalle preoccupazioni sollevate dalla persistenza di un modello tradizionale, tuttora in vigore nell'ambito dell'Istituto di Lettere dell'UFBA, e della forte resistenza da parte degli studenti nei confronti di un modello basato su un apprendimento autonomo e di collaborazione. Le nostre osservazioni sono fondate sulla ricerca-azione, una volta espletate le procedure di pianificazione, azione, osservazione e riflessione, applicate con l'intento di promuovere $i$ cambiamenti nel paradigma di insegnamento faccia a faccia tradizionale, mirando all'inserimento delle nuove tecnologie nella pratica didattica finalizzato alla costruzione di un apprendimento critico, riflessivo e collaborativo. Baseremo le nostre riflessioni sul lavoro di Paulo Freire circa la "pedagogia dell'autonomia" (1996), Lins e Souza riguardo l'alfabetizzazione digitale applicata alle tecnologie educative (2016), e Tripp (2005), per le caratteristiche e le funzioni di ricerca-azione. I risultati preliminari puntano alla pratica pedagogica con le nuove tecnologie, verso la costruzione di un apprendimento autonomo.

PAROLE CHIAVE: Insegnamento di LE; TICs; Língua Italiana; Collaborazione; Autonomia dell'apprendimento. 


\section{Uma pequena introdução}

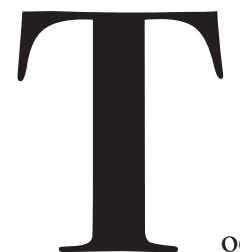

mano nos dias atuais. Tornou-se impensável viver sem o uso do computador, do tablet ou do celular nas mínimas coisas, desde a necessidade de comunicação imediata até resolução de problemas, como, por exemplo, transações comerciais via aplicativos. De fato, a tecnologia facilita a vida do homem moderno.

No âmbito da teoria da comunicação de massa, é sabido que o Determinismo Tecnológico, defendido por Robert Ezra Park, em 1940, e aprofundado por Marshall MacLuhan sobretudo entre os anos 60 e 70, prevê que os dispositivos tecnológicos modificariam as estruturas sociais e suas funções, instaurando uma verdadeira Aldeia Global, conceito criado por MacLuhan mesmo décadas antes do advento da internet. Por esse conceito, entende-se uma nova forma de conceber e de se relacionar com o mundo num grande emaranhado de conexões sociais, onde as noções de tempo e espaço tendem a relativizar-se e a esvaziar-se a partir da mediação das novas tecnologias da informação e da comunicação. Sem dúvida alguma, o mundo atual já não pode mais prescindir da tecnologia.

No campo da educação, as Tecnologias de Informação e de Comunicação (doravante TICs) alteram também a forma de ensinar. Sabe-se que os métodos tradicionais de ensino, em particular do ensino de línguas estrangeiras, por estarem centrados na estrutura da língua, sempre enfatizaram a figura do professor como centro desse processo de ensino e aprendizagem, relegando ao aluno o papel passivo na aquisição do conhecimento.

Dos anos 60 para cá, o processo de ensino e aprendizagem de idiomas tem sofrido alterações não só quanto aos motivos pelos quais se aprende, mas também quanto ao modo como se aprende. Assim, com uma abordagem bastante inovadora, o método comunicativo interativo tem colocado o aluno no centro do processo ensino e aprendizagem, forçando-o a tornar-se muito mais autônomo e ativo na construção do próprio conhecimento.

Não obstante toda essa difusão e uso dos recursos tecnológicos nos dias atuais e tão comuns na rotina de pesquisa entre os alunos de diversas faixas etárias e instituições de ensino, nota-se, no contexto acadêmico do Instituto de Letras da UFBA (doravante ILUFBA), ainda uma evidente centralização da figura do professor no processo de ensino e aprendizagem de LE e, por conseguinte, uma forte resistência, por parte dos discentes, a uma aprendizagem mais 
autônoma e, especificamente nas turmas de italiano, mais colaborativa. Diante dessa realidade, propus-me a indagar: Por que os alunos que frequentam os cursos de italiano oferecidos pelo ILUFBA insistem em preferir um modelo de aula expositiva, onde ele possa atuar timidamente, apesar de toda a autonomia exercida fora da sala de aula presencial, em redes sociais e em sites de busca? Quais seriam as dificuldades encontradas pelo docente para romper com o paradigma do ensino tradicional no âmbito do ILUFBA? De que modo poderiam transformar suas ações pedagógicas com vistas à promoção de uma aprendizagem mais autônoma e colaborativa em sala de aula presencial e a distância? Tais questionamentos me levaram a pensar em estratégias que visassem à ruptura desse quadro e à proposição de um novo modelo, visando à apropriação de uma maior autonomia no processo de construção da aprendizagem.

Pautada nessa pequena introdução, proponho-me, com esse artigo, a apresentar um relato de experiências obtidas a partir da aplicação de algumas estratégias de ensino e aprendizagem por meio das novas tecnologias, em turmas da graduação de italiano básico do ILUFBA, compostas por alunos provenientes, na sua maioria, dos cursos de Bacharelado Interdisciplinar, durante os semestres 2017.1 e 2017.2, objetivando promover uma maior interação, colaboração e autonomia de aprendizagem em aulas presenciais e a distância ${ }^{1}$.

Os resultados parciais apresentados até aqui estão vinculados ao meu projeto Ensino do italiano em AVA: abordagens, métodos e técnicas, o qual, por sua vez, compõe o grupo de pesquisa Ensino e aprendizagem de línguas estrangeiras com Novas Tecnologias, certificado pelo CNPq desde 2013.

Nosso aporte teórico está fundamentado nas postulações de Paulo Freire (1996), acerca do conceito de autonomia, o qual pressupõe, fundamentalmente, responsabilidade, envolvimento, comprometimento, disciplina, requisitos básicos, tanto para quem ensina quanto para quem aprende, visando à realização de um trabalho verdadeiramente colaborativo, reflexivo e crítico. Compreendo o conceito de autonomia da aprendizagem e liberdade, tal como apresentado por Freire, perfeitamente ligado ao conceito de letramento digital defendido por Lins e Souza (2016).

Complementando com Libório (2017) a educação online e o uso das novas tecnologias da comunicação e da informação com fins educativos, apesar do paradoxo que essa origina, têm contribuído para uma reflexão acerca do modo como se ensina e se aprende, resultando em uma promoção efetiva da inclusão digital e da democratização da educação, uma exigência do paradigma educacional atual. O que reforça em mim a esperança de estarmos trilhando o caminho certo rumo a um modelo educacional que tenha como objetivo central a formação de uma geração de alunos críticos, reflexivos, autônomos e emocionalmente maduros.

Por fim, minha pesquisa-ação tem respaldo na descrição do método apresentada por David Tripp (2005), uma vez que nossas ações visam a uma continuidade, a uma sistematização e ao aprimoramento das nossas práticas em direção à construção de uma autonomia da aprendizagem, essencial na educação online.

1 Aproveito o ensejo para agradecer pela colaboração do meu monitor, Robson Leite dos Santos, a quem devo muito pela realização desse trabalho e consequente publicação deste artigo. 


\section{Contextualizando o quadro}

Grande parte dos alunos da UFBA, talvez a maioria deles, enfrenta um crônico problema de deslocamento intercampi, embora a reitoria tenha providenciado um ônibus interno (Buzufba) para minimizar o problema. Em virtude disso, os atrasos nas aulas são muito comuns, o que acaba, dentre outros fatores, gerando um grave problema de assiduidade nas aulas presenciais. Além disso, diante do vasto programa previsto para as línguas de nível básico, apenas seis horas semanais de aula presencial não são suficientes para manter a motivação dos alunos, sobretudo daqueles que têm problemas de pontualidade e assiduidade. A situação se torna ainda mais crítica quando consideramos que, ao contrário de outras disciplinas, como o inglês, por exemplo, que oferece inúmeras possibilidades de contato diário com a língua, o contato com a língua italiana normalmente se limita às aulas presenciais. Com o crescimento de ofertas de atividades e de cursos online, já podemos contar atualmente com uma gama evidentemente maior de possibilidades de contato com o italiano também a distância. Diante disso, acreditando que é possível sanar antigos problemas de aprendizagem e de motivação, propomo-nos a ofertar pequenas e paulatinas atividades diárias a distância, ora para reforçar os conteúdos vistos em sala ora para antecipá-los através da metodologia da aula invertida (Chaquime e Mill, 2018), que consiste no envio preliminar de conteúdos a serem trabalhados na sala de aula presencial, provocando o aluno a assumir o protagonismo do processo de aprendizagem conforme seu ritmo pessoal. Assim, estando os alunos reunidos, a sala de aula presencial se transforma em um espaço de experimentação e de compartilhamento dos saberes apreendidos por meio dos conteúdos enviados.

\section{Observar, refletir, planejar, experimentar, avaliar}

Logo no primeiro dia de aula, tanto no semestre 2017.1 quanto no semestre 2017.2, apresentei à turma a proposta inicial de curso, contendo algumas ideias norteadoras acerca da metodologia e das avaliações. Ressaltei a importância do contato paulatino e diário com a língua estrangeira e apliquei um questionário para mapear o perfil dos alunos. Dentre as perguntas colocadas, estavam: "Qual o seu objetivo no curso de italiano? Quantas horas semanais você normalmente dedica ao estudo de uma língua estrangeira? Você aprende melhor estudando sozinho ou com a mediação do professor?". A essas, a maioria respondeu que tem pouco tempo para dedicar ao estudo de uma língua estrangeira fora da sala de aula presencial, devido à alta carga horária das disciplinas obrigatórias e optativas obrigatórias oferecidas pelos seus cursos de origem além da necessidade de ter um emprego, realidade de grande parte dos nossos alunos. Nesse sentido, optam por priorizar essas disciplinas, reduzindo a aprendizagem do italiano ao contexto da sala de aula presencial com a mediação do professor. 


\subsection{Das atividades a distância}

Dentre as propostas para a promoção de um contato diário com o italiano estava a realização de pequenas atividades a distância, via aplicativos, plataformas de ensino ou por email. O objetivo era experimentar diferentes recursos tecnológicos para mensurar as preferências dos alunos e a viabilidade de tais recursos como facilitadores da aprendizagem colaborativa.

Dentre as plataformas utilizadas, funcionaram muito bem as listas colaborativas via whatsapp, sobretudo para aquisição do léxico (aggettivi di nazionalità, professioni, descrizione física e caratteriale, etc), fixação das estruturas gramaticais (preposizioni e locuzioni prepositive, uso di essere e avere nei tempi composti, etc), além das produções orais por meio de mensagens de áudio e scioglilingua. Além dessas estratégias, adotei também a metodologia da aula invertida, normalmente antes da apresentação dos conteúdos nas aulas presenciais, a fim de trabalhar criticamente o background dos alunos e como foram construídos os conceitos de forma autônoma ou como warm up, objetivando uma aquisição prévia de vocabulário e a intensificação da produção oral em sala de aula.

Propus também que fosse construída uma lista colaborativa de músicas no spotify, conforme temas estabelecidos para cada mês (p. ex: mês de junho: Namorados - Canzoni romantiche; julho: Rock - Bande rock italiane, etc). A ideia era de que cada aluno deveria postar na lista uma música de sua preferência e, em seguida, na plataforma moodle, deveria escrever no fórum algum texto sobre aquela música. Deste modo, seria possível motivá-los a não só ampliar seu vocabulário e melhorar sua pronúncia como também a produzir textos em língua italiana.

\subsection{Das aulas presenciais}

As aulas presenciais eram muito dinâmicas, por meio de atividades em grupo ou em duplas, jogos, desafios, campeonatos, etc. Ao final de cada unidade, eram realizados campeonatos de trava línguas; o desafio era chegar até o final do semestre com os sons típicos do italiano bem consolidados e os trava-línguas falados com a maior velocidade possível. Quem vencesse, ganhava um prêmio. Essa estratégia ajudou bastante a reforçar a pronúncia do italiano.

Além da estratégia dos trava-línguas, eram feitos vídeos durante as leituras dos diálogos ou textos. Esses vídeos eram enviados aos alunos para que eles observassem o seu desempenho e corrigissem, comparando com o original, eventuais erros de pronúncia. Quando ocorria de alguém não autorizar a filmagem, eram registrados os respectivos áudios. Mas geralmente a turma concordava com o vídeo.

\subsection{Das avaliações escritas}

As avaliações escritas eram processuais, ao final de cada unidade, abordando todos os conteúdos trabalhados: gramática, funções comunicativas e vocabulário, produção escrita e 
elementos culturais. Terminada a prova, eram imediatamente corrigidas por autocorreção, comentadas e avaliadas qualitativa e quantitativamente pelos próprios alunos, inclusive a forma de elaboração das provas. Depois, eram entregues a mim para uma avaliação mais global. Interessante é que muitos deles tendiam a uma avaliação mais rigorosa e se atribuíam notas inferiores àquelas atribuídas por mim.

A aplicação de minitestes ao final de cada unidade permitiu-nos acompanhar melhor o processo de aprendizagem, pois nos dava a chance de retomar, nas unidades subsequentes, os conteúdos ainda não muito consolidados da unidade anterior.

\subsection{Tandem}

Outra estratégia que deu muito certo foi organizar encontros com nativos durante a segunda metade do curso, quando os alunos já se sentiam mais à vontade e seguros para estabelecerem uma conversa sobre elementos culturais. Ao final das unidades 4 e 5 do Nuovo Progetto Italiano, que é o material didático adotado nas minhas aulas, publicado pela editora Edilingua, foi possível retomar todo o conteúdo trabalhado por meio de debates sobre os vários tipos de café consumidos na Itália e também sobre viagens e festas. Essa atividade garantiu a consolidação das funções comunicativas e maior segurança na hora de se expressarem.

\subsection{Das produções escritas}

Desde o primeiro dia de aula, o aluno era submetido a atividades de produção oral e escrita. Conforme iam sendo aprendidos novos conteúdos, iam sendo, na mesma proporção, acrescentados à redação. A correção era feita em duas etapas: primeiramente pelos pares e, em seguida, por mim e pelo monitor. Ao final de cada unidade, a redação era reescrita, atualizada com os novos conteúdos, e entregue também registrada em áudio. Desta forma, era possível avaliar o texto escrito e a pronúncia. Por meio dessa estratégia, era possível ao aluno acompanhar o seu progresso a cada etapa, o que gerava uma motivação ainda maior para a realização das etapas seguintes.

\subsection{Da avaliação oral final}

Para encerrar o programa de avaliações, foi proposto aos alunos que fizessem, a partir dos temas propostos por mim ou combinados conjuntamente, apresentações por meio de um recurso tecnológico de sua preferência. A maioria preferiu a elaboração de vídeos (dublagens, paródias, traduções ou adaptações de obras, apresentação de programas culinários, dentre outros), que resultaram em excelentes trabalhos. 


\subsection{Sobre o feedback}

No início do semestre, solicitei-lhes que construíssem um diário de bordo, contendo as suas impressões sobre a aplicação dos recursos tecnológicos utilizados: se favoreceram a aprendizagem ou não e porquê. Esses diários constituíram o relatório de avaliação do curso e do próprio desempenho, entregue no final do semestre, em português.

Pedi que avaliassem, dentre outras coisas, a proposta do curso, a metodologia, os recursos tecnológicos utilizados nas aulas presenciais e a distância. O objetivo dessa atividade era reforçar no aluno, tanto a reflexão crítica do seu próprio desempenho quanto a noção de que ele é parte essencialmente ativa durante todo o trabalho desenvolvido. No geral, o envolvimento com a avaliação desses quesitos foi muito positiva, pois todos demonstraram muito interesse em manifestar um parecer.

De acordo com esse feedback podemos tecer, portanto, algumas considerações.

\section{Semestre 2017.1}

Por ter sido um período bastante regular em termos de continuidade das aulas, isto é, praticamente sem interrupções decorrentes de paralisações várias (ônibus, professores, etc), foi o semestre em que melhor pudemos desenvolver o trabalho e observar os resultados. A turma manteve-se motivada durante todo o percurso, respondendo positivamente a todas as propostas implementadas. Mesmo quando alguma estratégia não funcionava muito bem, eles respondiam criticamente propondo soluções:

"As atividades à distância foram aplicadas via Whatsapp, Google Classroom e Spotify. A interação via Whatsapp mostrou-se valiosa a fim de manter os alunos engajados, praticando as estruturas aprendidas durante as aulas presenciais, contudo o uso das potencialidades do Google Classroom foi limitado a servir de acervo do material. Uma tentativa foi passar uma das atividades escritas a ser entregue via GC, o que foi algo bem interessante e talvez possa ser expandido no futuro".

Constatamos ainda que o spotify não atendeu muito bem às nossas expectativas por conter uma lista fechada de músicas. Alguns alunos reclamaram, por exemplo, que desejavam acrescentar à lista determinada música que não estava disponível no aplicativo. Nesse sentido, o Youtube parece-nos uma alternativa apropriada, cujo uso será por mim melhor planejado a fim de implementá-lo nos próximos semestres.

Quanto às atividades pelo whatsapp, há que se ressaltar a importância de um acurado planejamento da atividade a fim de não comprometer a realização da tarefa. Por exemplo, durante as unidades 2 e 3 do Nuovo Progetto Italiano, em que aprendemos sobre a descrição da casa e localização dos objetos, postei três imagens para que cada aluno descrevesse apenas um dos detalhes: ou localização dos objetos, usando preposições ou locuções prepositivas, ou descrição dos cômodos e características da casa ou apartamento. Os alunos mais atentos às notifi- 
cações das mensagens eram os primeiros a realizarem a tarefa; outros, não atentando muito para o enunciado, faziam uma redação completa, esgotando todas as possibilidades de exploração da imagem, de modo que os demais ficavam sem ter o que dizer sobre a atividade. Essa ocorrência me fez atentar para a necessidade de um melhor planejamento, dividindo a turma em pequenos grupos, desde o início do semestre, e postando imagens ou tarefas suficientes para cada grupo.

As listas colaborativas resultaram em excelente estratégia para aquisição de vocabulário e fixação de tópicos gramaticais. Por exemplo, ensinar as regras de uso dos auxiliares Essere e Avere sempre representou um nó para as turmas de básico, já que normalmente os alunos não são muito aptos a decorarem as enfadonhas regras gramaticais fora de contexto. Tive a ideia, portanto, de construir uma lista colaborativa contendo os verbos mais usados e que são conjugados com o auxiliar Essere. Essa estratégia garantia total motivação, já que os primeiros a realizarem a tarefa encontravam mais facilidade, enquanto que os últimos tinham mais dificuldade para postar alguma resposta que não tivesse ainda sido usada. Construída a lista, cada aluno tinha que elaborar uma frase, usando um dos verbos postados no passato prossimo. Nessa etapa da atividade, surgiam dúvidas do tipo: "Maria è cambiata casa”, e, nesse momento, eu intervinha para explicar as regras de transitividade do verbo.

\section{Semestre 2017.2.}

Infelizmente, o feedback da turma do segundo semestre já não foi tão positivo, em virtude da irregularidade das aulas, decorrente de paralisações ou greves. Isso ocasionou um acúmulo de atribuições gerais para os alunos, de modo que as atividades a distância, ao invés de promoverem a motivação e a colaboração, se transformaram em um stress a mais na sua rotina acadêmica. Sabedores de que o filtro afetivo alto é um fator que pode interferir negativamente na aprendizagem (Callegari, 2006), decidimos adaptar nossa proposta, limitando-a à sala de aula presencial por meio de jogos, aplicativos, sites, recursos importantes que ajudaram a minimizar a falta de motivação e de interação. Contudo, é evidente a diferença entre os resultados do primeiro e do segundo semestres, tanto pelo quadro geral de notas (o que demonstrou um reflexo do nível de aprendizagem) quanto pela redução da quantidade de horas dedicadas ao estudo da língua.

\section{Considerações finais}

Todos nós professores sabemos que o sucesso das nossas metodologias está condicionado ao meio, à época e ao público alvo. Nenhuma turma é igual à outra e tampouco nenhum semestre é igual ao outro. Assim, uma mesma metodologia pode funcionar num contexto e ser um fiasco, em outro. Após aplicar e avaliar os procedimentos adotados nos dois semestres acima apresentados, mesmo com as devidas adaptações metodológicas, os resultados em 2017.2 
frustraram um pouco as expectativas projetadas no início do período letivo. Diante disso, nossa experiência confirma nossa hipótese inicial de que persistir na proposta de promover um contato diário com o idioma garante melhores resultados quanto à manutenção da motivação, à diminuição do filtro afetivo e, por conseguinte, do compartilhamento dos saberes adquiridos por meio do exercício da autonomia no processo de construção da aprendizagem.

É possível concluir também que os alunos envolvidos nessa proposta experimental ainda não estão amadurecidos o suficiente para assumirem o controle do processo de construção da sua aprendizagem sozinhos; portanto, não estão preparados, por enquanto, para a realização de cursos totalmente a distância. Entretanto, os resultados, sobretudo do primeiro semestre, demonstram que devemos insistir no percurso de transição da modalidade presencial para a modalidade a distância, construindo paulatinamente os pilares de uma aprendizagem autônoma, reflexiva e colaborativa, rumo a um modelo de ensino e aprendizagem totalmente a distância.

Por fim, agradeço o imenso apoio da Congregação do Instituto de Letras ao aprovar os meus projetos de monitoria para a realização desse trabalho. A colaboração do monitor em todo esse processo foi de suma importância, porque além do apoio para o controle de todos esses dados e análise dos resultados, a identificação com os alunos favoreceu a diminuição do filtro afetivo e a espontaneidade no desempenho dos discentes.

\section{Referèncias}

CALLEGARI, M. O. V. Reflexões sobre o modelo de aquisição de segundas línguas de Stephen Krashen - uma ponte ente a teoria e a prática em sala de aula. Campinas, 2006. Disponível em: <http:// www.scielo.br/pdf/tla/v45n1/a06.pdf $>$.

CHAQUIME, L. P., MILL, D. Metodologias ativas. Em MILL, D. (Org.). Dicionário crítico de educação e tecnologias e de educação a distância. Campinas, SP: Papirus, 2018.

FREIRE, P. Pedagogia da autonomia. 1996. Disponível em: < http://plataforma.redesan.ufrgs.br/biblioteca/pdf bib.php?COD ARQUIVO=17338>.

LIBÓRIO, L. M. E. Tecnologías de Información y Comunicación y la Enseñanza del Español on line: un análisis de discursos de las disciplinas virtuales del curso de Letras Español a distancia de la UAB-UESPI. In: Caracol, São Paulo: n.13, jan./jun. 2017. Disponível em: <http://www.revistas.usp.br/ caracol/article/view/123129>.

LINS, E. F; SOUZA, F. M. Letramento e suas pluralidades: percurso conceitual e práticas digitais. In: SANTOS, E. C; et al. (Orgs.). Tecnologias educacionais e inovação: diálogos e experiências. Curitiba: Appris, 2016.

TRIPP, D. Pesquisa-ação: uma introdução metodológica. Tradução de Lólio Lourenço de Oliveira. Educação e Pesquisa, São Paulo: v. 31, n. 3, p. 443-466, set./dez. 2005.

Recebido em: 15/06/2018

Aprovado em: 01/11/2018 